\title{
PENGARUH KADAR FILLER ABU BATU KAPUR DAN ABU TEMPURUNG KELAPA TERHADAP KARAKTERISTIK MARSHALL PADA CAMPURAN ASPAL BETON AC-BC
}

\author{
Muhammad Yacob ${ }^{1}$, Wesli $^{2}$ \\ Jurusan Teknik Sipil, Fakultas Teknik, Universitas Malikussaleh \\ Email: yacob.w2r@gmail.com ${ }^{1}$ ), wesli@unimal.ac.id ${ }^{2}$
}

\begin{abstract}
Abstrak
Perkerasan jalan AC-BC yang terlalu dini rusak tidak sesuai dengan umur rencana biasanya di sebabkan oleh faktor beban berlebih dan mutu campuran aspal. Dewasa ini telah banyak diteliti tentang bahan pengisi (filler) dari material lokal yang banyak digunakan dan ramah lingkungan untuk memodifikasi sifatsifat aspal dalam campuran aspal beton sehingga dapat memperbaiki kinerja perkerasan dari sisi nilai parameter Marshall. Penelitian ini untuk melihat pengaruh kadar filler abu batu kapur (ABK) dan abu tempurung kelapa (ATK) pada perkerasan jalan AC-BC dengan metode Spesifikasi Umum Bina Marga Revisi 3 yang ditinjau dari karakteristik Marshall, dengan membandingkan perilaku campuran AC-BC yang menggunakan filler ABK dan ATK dengan campuran normal. Pada penelitian ini KAO yang didapatkan sebesar $6 \%$ dan untuk benda uji dengan filler ABK dan ATK dengan variasi 100:0; 0:100; 25:75; 50:50 dan75:25. Hasil pengujian perbandingan nilai stabilitas menunjukkan nilai stabilitas yang didapat dari penggunaan filler ABK dan ATK dengan metode spesifikasi Bina Marga 2010 revisi 3 meningkat dibandingkan dengan tanpa adanya penggunaan filler ABK dan ATK yaitu nilai stabilitasnya sebesar 1562,95 $\mathrm{kg}$, sedangkan campuran normal sebesar 1430,19 kg. Untuk nilai density, VFWA, stabilitas, dan flow mengalami peningkatan pada semua variasi, sedangkan nilai VMA, VITM, dan MQ mengalami penurunan dan masih dalam spesifikasi yang disayaratkan, selanjutnya untuk nilai durabilitas adalah $80,3 \%$, nilai tersebut belum memenuhi nilai yang disyaratkan. Pada penelitian ini hanya pada variasi filler 25\% ABK dan 75\% ATK yang menunjukan seluruh nilai parameter Marshall telah memenuhi Spesifikasi Bina Marga 2010 Revisi, hal ini menunjukkan bahwa ada pengaruh durabilitas dalam variasi campuran filler pada aspal beton AC-BC.
\end{abstract}

Kata kunci: Abu Batu Kapur, Abu Tempurung Kelapa, Marshall

\section{Pendahuluan}

Batuan kapur (limestone) termasuk batuan sedimen, batuan ini terdiri dari kalsium karbonat $\left(\mathrm{CaCO}_{3}\right)$ mencapai $95 \%$, selain kalsium karbonat batu kapur juga megandung silika, magnesit, alumina serta beberapa senyawa lainnya namun dalam jumlah yang lebih kecil. Sedangkan Abu tempurung kelapa mengandung senyawa karbon non-polar sama seperti senyawa karbon yang terdapat pada aspal, diharapkan penambahan Abu Batu Kapur (ABK) dan Abu Tempurung Kelapa (ATK) sebagai filler akan dapat memperbaiki kinerja campuran aspal beton.

Penggunaan filler pada campuran aspal beton banyak diteliti untuk mendapatkan kinerja campuran yang baik dan ekonomis, namun untuk jenis bahan tertentu harganya dipasaran sudah mulai mahal dan susah ditemukan di daerah-daerah tertentu sehingga campuran aspal menjadi tidak ekonomis, selain itu perlu suatu upaya pemanfaatan material local dan bagaimana bahan lokal

Pengaruh Kadar Filler Abu Batu Kapur Dan Abu Tempurung Kelapa Terhadap Karakteristik Marshall Pada Campuran Aspal Beton AC-BC-Muhammad Tacob, Wesli 
seperti tempurung kelapa yang persediaannya melimpah di Provinsi Aceh dapat bermanfaat, hasil sampingan buah kelapa seperti tempurung jika tidak dimanfaatkan secara optimal nantinya menjadi limbah sehingga menggangu lingkungan, ada usaha untuk memanfaatkan limbah ini salah satunya kemungkinan abu arang tempurung kelapa digunakan sebagai filler dalam campuran aspal beton, namun hal ini juga diperlukan peran tanah dasar dalam member daya dukungnya dalam parameter CBR. Semakin kecil nilai daya dukung tanah semakin besar tebal lapisan perkerasan yang dibutuhkan, menunjukan bahwa semakin kecil nilai CBR semakin kecil pula nilai daya dukung tanah yang diperoleh (Said Jalalul Akbar, Wesli, 2014)

Tujuan penelitian ini adalah untuk mengetahui seberapa besar pengaruh campuran aspal beton AC-BC dengan menggunakan filler abu batu kapur dan abu tempurung kelapa dan bagaimana variasi campuran optimal dalam mencapai stabilitas dan flow yang disyaratkan dengan penggunaan abu batu kapur dan abu tempurung kelapa.

\section{Tinjauan Kepustakaan}

Asphal Concrete Binder Course $(A C-B C)$ adalah lapisan perkerasan yang terletak dibawah lapisan aus. Tidak berhubungan langsung dengan cuaca, tetapi perlu memiliki stabilitas untuk memikul beban lalulintas yang dilimpahkan oleh roda kendaraan. Sesuai dengan fungsi laston AC-BC juga disebut sebagai lapis pengikat. AC-BC juga berfungsi sebagai perekat dalam campuran aspal beton yang sangat penting dipertahankan kemampuannya terhadap kelekatan dan titik kelenturannya. (Sukirman, 2003)

Ketentuan dan persyaratan tentang sifat-sifat campuran Asphal Concrete Binder Course $(A C-B C)$ harus sesuai dan memenuhi yang dipersyaratkan oleh Spesifikasi Umum Bina Marga 2010 (Revisi 3) seperti diperlihatkan pada Tabel 1.

Tabel 1 Ketentuan Sifat-sifat Campuran Laston (AC)

\begin{tabular}{|c|c|c|c|c|}
\hline \multirow{2}{*}{\multicolumn{2}{|c|}{ Sifat-sifat Campuran }} & \multicolumn{3}{|c|}{ Laston } \\
\hline & & Lapis Aus & \multirow{2}{*}{$\frac{\text { Lapis Antara }}{75}$} & \multirow{2}{*}{$\begin{array}{c}\text { Pondas } \\
112^{(1)}\end{array}$} \\
\hline Jumlah tumbukan per bidang & & & & \\
\hline \multirow{2}{*}{$\begin{array}{c}\text { Rasio partikel lolos ayakan } 0,075 \mathrm{~mm} \\
\text { dengan kadar aspal efektif }\end{array}$} & Min & \multicolumn{3}{|c|}{1,0} \\
\hline & Maks & \multicolumn{3}{|c|}{1,4} \\
\hline \multirow{2}{*}{ Rongga dalam campuran $(\%)^{(2)}$} & Min & \multicolumn{3}{|c|}{3,0} \\
\hline & Maks & \multicolumn{3}{|c|}{5,0} \\
\hline Rongga dalam agregat (VMA) (\%) & Min & 15 & 14 & 13 \\
\hline Rongga Terisi Aspal (\%) & Min & 65 & 65 & 65 \\
\hline Stabilitas Marshall $(\mathrm{Kg})$ & Min & & 800 & $1800^{(1)}$ \\
\hline \multirow{2}{*}{ Pelelehan (mm) } & Min & & 2 & 3 \\
\hline & Maks & & 4 & $6^{(1)}$ \\
\hline $\begin{array}{l}\text { Stabilitas Marshall Sisa (\%) setelah } \\
\text { perendaman selama } 24 \text { jam, } 60^{\circ} \mathrm{C}^{(3)}\end{array}$ & Min & \multicolumn{3}{|c|}{90} \\
\hline $\begin{array}{l}\text { Rongga dalam campuran (\%) pada } \\
\text { Kepadatan membal (refusal) }^{(4)}\end{array}$ & Min & \multicolumn{3}{|c|}{2} \\
\hline
\end{tabular}

Sumber: Spesifikasi Umum Bina Marga 2010 (Revisi 3) 


\subsection{Abu Batu Kapur}

Batuan kapur (limestone) termasuk batuan sedimen. Batuan kapur ini pada dasarnya berasal dari sisa-sisa organisme laut seperti kerang, siput laut, radiolarit, tumbuhan/binatang karang, dsb yang telah mati.

Batuan ini berwarna putih, kelabu yang terdiri dari kalsium karbonat $\left(\mathrm{CaCO}_{3}\right)$ mencapai $95 \%$, selain kalsium karbonat limestone juga mengandung silica, alumina, dan magnesit serta beberapa senyawa lainnya namun dalam jumlah yang lebih kecil. (Wardiyatmok,o 2006)

Tabel 2 Komposisi Kimia Batu Kapur

\begin{tabular}{|c|c|c|c|}
\hline No. & Nama Senyawa & Satuan & Hasil \\
\hline 1 & $\mathrm{CaCO}_{3}$ & $\%$ & 95,20 \\
\hline 2 & $\mathrm{SiO}_{2}$ & $\%$ & 1,20 \\
\hline 3 & $\mathrm{MgCO}_{3}$ & $\%$ & 0,90 \\
\hline 4 & $\mathrm{H}_{2} \mathrm{O}$ & $\%$ & 0,00 \\
\hline
\end{tabular}

Sumber: Rosenqvist T, 2004

\subsection{Abu Tempurung Kelapa}

Abu tempurung kelapa adalah hasil dari proses pembakaran tempurung kelapa. Sebagai filler abu arang terpurung kelapa mengandung lignin, selusa, mektosil dan berbagai mineral lainnya. Struktur keras disebabkan silika $\left(\mathrm{SiO}_{2}\right)$ yang cukup tinggi, dan kandungan arang tempurung kelapa terdiri dari karbon non popular yang besarnya $91 \%$ seperti terdapat pada aspal. (Berry, 1991)

\section{Tabel 3 Komposisi dan Berat Jenis Abu Tempurung Kelapa}

\begin{tabular}{|c|c|c|c|}
\hline No. & Parameter Uji & Satuan & Hasil \\
\hline 1 & Kadar Air & $\%$ & 3,83 \\
\hline 2 & Kadar Karbon & $\%$ & 91,38 \\
\hline 3 & Kadar Abu & $\%$ & 4,79 \\
\hline 4 & Berat Jenis & $\mathrm{gr}^{\prime} \mathrm{cm}^{3}$ & 0,5722 \\
\hline \multicolumn{4}{|c}{ Sumber. Berry, 1991 }
\end{tabular}

Sumber: Berry, 1991

\section{Metode Penelitian}

Tahapan-tahapan pelaksanaan penelitian ini mencakup persiapan, pelaksanaan dan analisa data. Persiapan dimulai dengan dilakukan studi literatur terlebih dahulu dengan mengumpulkan referensi berupa buku atau jurnal yang berhubungn dengan judul dari penelitian ini, kemudian dilanjutkan dengan persiapan alat yang sudah tersedia di laboratorium serta pengadaan material yang didapatkan dari laboratorium berupa aspal Penetrasi 60/70 dan agregat didapatkan dari PT. BBC Lhokseumawe. Selanjutnya dilakukan pengujian agregat kasar dan agregat halus yang melingkupi pengujian analisa saringan, berat jenis dan, penyerapan air pada agregat, sedangkan untuk filler hanya dilakukan pengujian analisa saringan saja.

Setelah pemeriksaan material dilakukan jika memenuhi nilai yang disyaratkan penelitian dapat dilanjutkan dengan membuat rancangan mix design, 
tetapi jika tidak memenuhi spesifikasi yang disyaratkan harus menyiapkan material yang lain.

Langkah selanjutnya dilakukan perencanaan mix design lalu dilanjutkan dengan pembuatan benda uji kadar aspal optimum (KAO), benda uji dibuat 3 buah per variasi aspal, lalu benda uji dilakukan pengujian untuk mendapatkan nilai KAO. Setelah didapatkan nilai KAO kemudian dilanjutkan dengan pembuatan benda uji untuk pengujian Marshall, benda uji dibuat 5 benda uji setiap variasinya dengan variasi perbandingan kadar filler abu batu kapur dan abu tempurung kelapa dengan perbandingan 100\%:0\%, 0\%:100\%, 25\%:75\%, 50\%:50\% dan $75 \%: 25 \%$.

Berikutnya benda uji direndam selama 1-24 jam dalam waterbath, kemudian uji standar stabilitas dan flow dengan alat Marshall. Setelah itu dilanjutkan dengan pembuatan benda uji untuk pengujian menghitung durabilitas, benda uji dibuat hanya 5 benda uji pada variasi yang menunjukan nilai pengujian Marshall paling optimum.

Kemudian uji standar stabilitas dan flow dengan alat Marshall dan didapat hasil untuk dilakukan analisa data dan pembahasan serta diambil kesimpulan dan saran.

Proporsi agregat yang digunakan untuk Asphal Concrete Binder Course $(A C-B C)$ pada penelitian ini sesuai dan memenuhi yang dipersyaratkan oleh Spesifikasi Umum Bina Marga 2010 (Revisi 3) seperti diperlihatkan pada Tabel 4.

Tabel 4 Proporsi Agregat Yang Digunakan Untuk Aspal Beton AC-BC

\begin{tabular}{|c|c|c|c|c|c|c|}
\hline \multicolumn{2}{|c|}{ Saringan } & Spesifikasi Bina & \multicolumn{4}{|c|}{ Target Rencana } \\
\hline $\begin{array}{l}\text { Metrik } \\
(\mathrm{mm})\end{array}$ & ASTM & Titik Kontrol & $\begin{array}{c}\text { Lolos } \\
(\%)\end{array}$ & $\begin{array}{c}\text { Tertahan } \\
(\%)\end{array}$ & $\begin{array}{l}\text { Total } \\
(\%)\end{array}$ & $\begin{array}{c}\text { Per Benda } \\
\text { Uji } \\
(\mathrm{gr})\end{array}$ \\
\hline 19 & $3 / 4 "$ & $90-100$ & 100 & - & \multirow{5}{*}{60} & \\
\hline 12,5 & $1 / 2 "$ & $75-90$ & 89 & 11 & & 240 \\
\hline 9,5 & $3 / 8 ”$ & $66-82$ & 80 & 9 & & 72 \\
\hline 4,75 & No. 4 & $46-64$ & 58 & 22 & & 240 \\
\hline 2,36 & No. 8 & $30-49$ & 40 & 18 & & 168 \\
\hline 1,18 & No. 16 & $18-38$ & 31 & 9 & \multirow{5}{*}{35} & 180 \\
\hline 0,500 & No. 30 & $12-28$ & 23 & 8 & & 84 \\
\hline 0,300 & No. 50 & $7-20$ & 18 & 5 & & 48 \\
\hline 0,150 & No. 100 & $5-13$ & 8 & 10 & & 48 \\
\hline 0,075 & No. 200 & $4-8$ & 5 & 3 & & 60 \\
\hline \multicolumn{2}{|c|}{ Pan } & & & 5 & 5 & 60 \\
\hline \multicolumn{4}{|c|}{ Total } & 100 & 100 & 1200 \\
\hline
\end{tabular}

Proporsi filler yang digunakan sesuai dengan variasi campurannya diperlihatkan pada Tabel 5 
Tabel 5 Proporsi Filler Yang Digunakan

\begin{tabular}{|c|c|c|c|c|c|}
\hline \multirow{2}{*}{ Filler } & \multirow{2}{*}{$\begin{array}{c}\text { ABK } \\
(\mathrm{gr})\end{array}$} & \multirow{2}{*}{$\begin{array}{c}\text { ATK } \\
(\mathrm{gr})\end{array}$} & \multirow{2}{*}{$\begin{array}{c}\text { Jumlah } \\
\text { Benda Uji }\end{array}$} & \multicolumn{2}{|c|}{ Jumlah Filler (gr) } \\
\cline { 5 - 6 } & & & & ABK & ATK \\
\hline $100: 0$ & 60 & 0 & 5 & 300 & 0 \\
\hline $0: 100$ & 0 & 60 & 5 & 0 & 300 \\
\hline $25: 75$ & 15 & 45 & 5 & 75 & 225 \\
\hline $50: 50$ & 30 & 30 & 5 & 150 & 150 \\
\hline $75: 25$ & 45 & 15 & 5 & 225 & 75 \\
\hline \multicolumn{3}{|c|}{ Total } & 25 & 750 & 750 \\
\hline
\end{tabular}

Benda uji yang digunakan terdiri dari 3 jenis pengujian yaitu benda uji untuk Kadar Aspal Optimum (KAO), Benda Uji untuk Marshall yaitu Uji Parameter dan Benda Uji untuk Durabilitas (Menghitung Durabilitas Marshall) seperti diperlihatkan pada Tabel 6

Tabel 6 Penentuan Jumlah Benda Uji

\begin{tabular}{|c|c|c|c|c|c|c|}
\hline \multicolumn{6}{|c|}{ 1. Banda Uji Kadar Aspal Optimum (KAO) } & \multirow[t]{2}{*}{ Total } \\
\hline $\begin{array}{c}\text { Variasi Kadar Aspal } \\
(\%)\end{array}$ & 4,5 & 5 & 5,5 & 6 & 6,5 & \\
\hline Jumlah Benda Uji & 3 & 3 & 3 & 3 & 3 & 15 \\
\hline \multicolumn{7}{|c|}{ 2. Benda Uji Marshall (Uji Parameter Marshall) } \\
\hline $\begin{array}{c}\text { Variasi Kadar ABK dan ATK } \\
(\%)\end{array}$ & 100:0 & $0: 100$ & $25: 75$ & $50: 50$ & $75: 25$ & \\
\hline Jumlah Benda Uji & 5 & 5 & 5 & 5 & 5 & 25 \\
\hline \multicolumn{7}{|c|}{ 3. Benda Uji Durabilitas (Menghitung Durabilitas) } \\
\hline \multicolumn{6}{|c|}{ Variasi Yang Menghasilkan Nilai Parameter Marshall Maksimum } & 5 \\
\hline \multicolumn{6}{|c|}{ Total Benda Uji } & 45 \\
\hline
\end{tabular}

\section{Hasil dan Pembahasan}

\subsection{Pengujian Material untuk Campuran AC-WC}

Pada pengujian Kadar Aspal Optimum (KAO) dilakukan terhadap parameter density, Void in Mineral Aggregate (VMA), Void In The Mix (VITM), Voids Filled With Asphalt (VFWA), Stability, Flow dan Marshall Quotient (MQ) sesuai dengan spesifikasi yang disyaratkan.

Hasil pengujian harus memenuhi syarat spesifikasi masing-masing parameter dan yang diperoleh adalah hasil pengujian KAO, hasil pengujian Marshall standar, dan hasil durabilitas campuran aspal beton AC-BC diperlihatkan pada Tabel 7 dan Tabel 8. 
Tabel 7 Hasil pengujian Marshall untuk menentukan KAO pada benda uji

\begin{tabular}{|c|c|c|c|c|c|c|c|}
\hline \multirow{2}{*}{ No } & \multirow{2}{*}{ Kriteria } & \multirow{2}{*}{ Spesifikasi } & \multicolumn{5}{|c|}{ Kadar Aspal (\%) } \\
\cline { 4 - 8 } & & 4,5 & 5,0 & 5,5 & 6,0 & 6,5 \\
\hline 1 & Density & - & 2,296 & 2,306 & 2,311 & 2,295 & 2,324 \\
\hline 2 & VMA & Min 14 & 13,719 & 13,752 & 13,954 & 14,949 & 14,248 \\
\hline 3 & VITM & $3,0-5,0$ & 6,229 & 5,204 & 4,369 & 4,430 & 2,630 \\
\hline 4 & VFWA & Min 65 & 54,889 & 62,223 & 68,939 & 70,368 & 81,590 \\
\hline 5 & Stability & Min 800 & 1271,84 & 1398,89 & 1462,35 & 1430,19 & 1444,87 \\
\hline 6 & Flow & $2,0-4,0$ & 3,867 & 4,167 & 4,293 & 3,917 & 4,387 \\
\hline 7 & MQ & Min 250 & 333,071 & 339,243 & 343,958 & 374,232 & 330,279 \\
\hline
\end{tabular}

Tabel 8 Penentuan Kadar Aspal Optimum Campuran AC-BC

\begin{tabular}{|c|c|c|c|c|c|c|c|}
\hline \multirow{2}{*}{ No } & \multirow{2}{*}{ Kriteria } & \multirow{2}{*}{ Spesifikasi } & \multicolumn{5}{|c|}{ Kadar Aspal (\%) } \\
\hline & & & 4,5 & 5,0 & 5,5 & 6,0 & 6,5 \\
\hline 1 & Density & - & & & & & \\
\hline 2 & VMA & Min 14 & & & & & \\
\hline 3 & VITM & $3,0-5,0$ & & & & & \\
\hline 4 & VFWA & Min 65 & & & & & \\
\hline 5 & Stability & $\operatorname{Min} 800$ & & & & & \\
\hline 6 & Flow & $2,0-4,0$ & & & & & \\
\hline 7 & MQ & $\operatorname{Min} 250$ & & & & & \\
\hline
\end{tabular}

Berdasarkan hasil analisis untuk semua parameter Marshall maka didapat nilai Kadar Aspal Optimum (KAO) pada kadar aspal 6\%.

Tabel 9 Hasil Uji Parameter Marshall (Standar Stabilitas)

\begin{tabular}{|c|c|c|c|c|c|c|c|}
\hline \multirow{2}{*}{ No } & \multirow{2}{*}{ Kriteria } & \multirow{2}{*}{ Spesifikasi } & \multicolumn{5}{|c|}{ Kadar Filler ABK : ATK $(\%)$} \\
\cline { 4 - 8 } & & & $100: 0$ & $0: 100$ & $25: 75$ & $50: 50$ & $75: 25$ \\
\hline 1 & Density & - & 2,297 & 2,300 & 2,302 & 2,301 & 2,301 \\
\hline 2 & VMA & Min 14 & 14,900 & 14,771 & 14,705 & 14,722 & 14,726 \\
\hline 3 & VITM & $3,0-5,0$ & 4,375 & 4,230 & 4,156 & 4,175 & 4,180 \\
\hline 4 & VFWA & Min 65 & 70,648 & 71,381 & 71,772 & 71,672 & 71,641 \\
\hline 5 & Stability & Min 800 & 1474,81 & 1434,10 & 1516,36 & 1520,58 & 1562,95 \\
\hline 6 & Flow & $2,0-4,0$ & 4,850 & 4,475 & 3,910 & 4,740 & 4,984 \\
\hline 7 & MQ & Min 250 & 320,861 & 329,812 & 388,251 & 324,316 & 314,367 \\
\hline
\end{tabular}

Pengujian benda uji menggunakan abu batu kapur dan abu tempurung kelapa ini merupakan hasil dari pengujian langsung terhadap benda uji dengan menggunakan kada aspal 6\% yang didapat dari pencarian nilai KAO. 


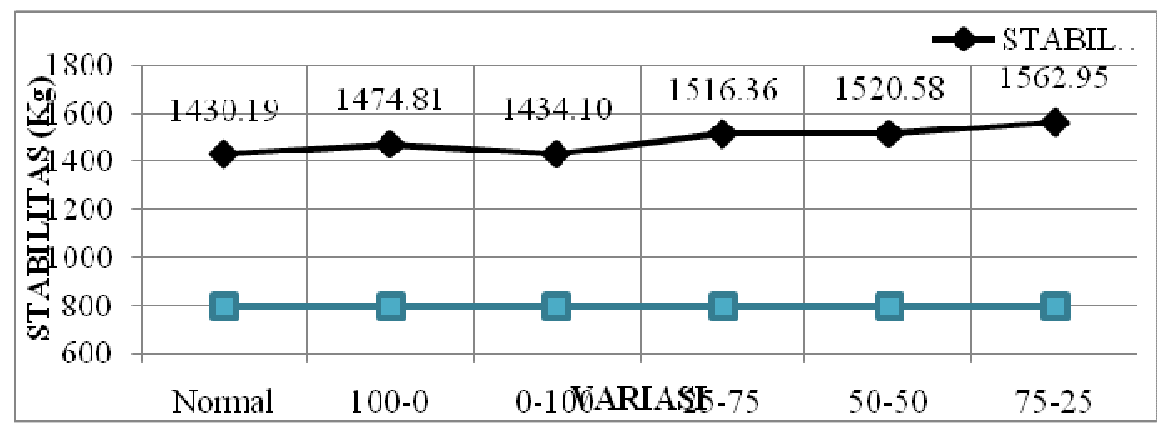

Gambar 1 Pengaruh Kadar Filler Terhadap Stabilitas

Berdasarkan grafik diatas dapat dilihat bahwa penggunaan abu batu kapur dan abu tempurung kelapa dapat meningkatkan nilai stabilitas. Nilai stabiliatas tertinggi adalah pada variasi 75:25.

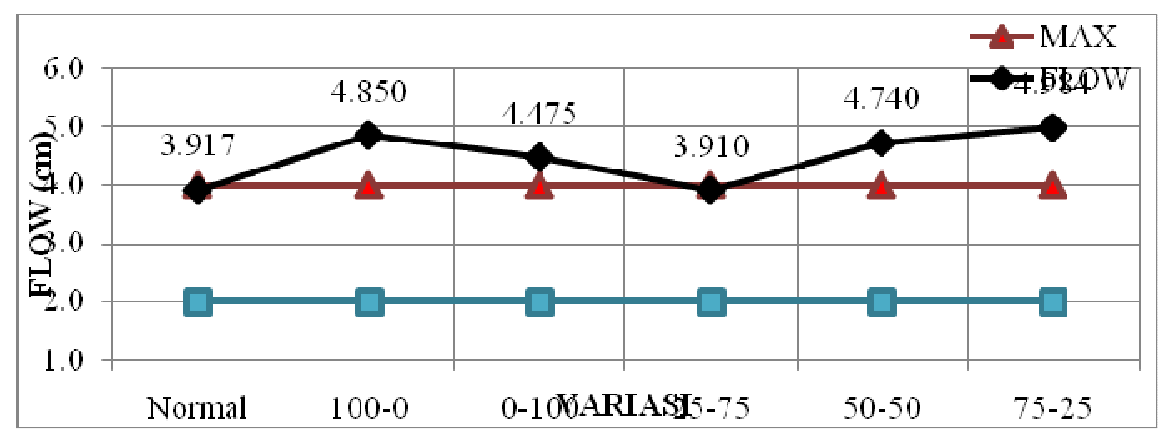

Gambar 2 Pengaruh Kadar Filler Terhadap Flow

Berdasarkan grafik diatas dapat dilihat bahwa penggunaan abu batu kapur dan abu tempurung kelapa dapat meningkatkan nilai Flow. Nilai flow terendah adalah pada variasi 25:75 sedangkan nilai flow tertinggi adalah pada variasi 75:25.

Tabel 10 Hasil Uji Parameter Marshall Pada Perendaman 1 Hari

\begin{tabular}{|c|c|c|c|}
\hline \multirow{2}{*}{ No } & \multirow{2}{*}{ Kriteria } & \multirow{2}{*}{ Spesifikasi } & Kadar Filler ABK : ATK (\%) \\
\cline { 4 - 4 } & & - & $25: 75$ \\
\hline 1 & Density & Min 14 & 2,245 \\
\hline 2 & VMA & $3,0-5,0$ & 16,826 \\
\hline 3 & VITM & Min 65 & 6,539 \\
\hline 4 & VFWA & Min 800 & 61,190 \\
\hline 5 & Stability & $2,0-4,0$ & 1210,99 \\
\hline 6 & Flow & Min 250 & 5,130 \\
\hline 7 & MQ & & 237,372 \\
\hline
\end{tabular}

Dari hasil pengujian benda uji campuran aspal beton dengan filler abu batu kapur dan abu tempurung kelapa pada campuran aspal beton AC-BC yang setelah dilalakukan perendaman 1 hari didapatkan nilai density sebesar 2,245 $\mathrm{gr} / \mathrm{cm}^{3}$, VMA sebesar 16,826\%, VITM sebesar 6,539\%, VFWA sebesar 61,190\%, 
stabilitas sebesar 1210,99 $\mathrm{Kg}$, flow sebesar 5,130 cm, MQ sebesar 237,190 $\mathrm{Kg} / \mathrm{cm}$.

Tabel 11 Perhitungan Durabilitas Marshall

\begin{tabular}{|c|c|c|c|c|}
\hline \multirow{2}{*}{ Variasi Filler } & \multirow{2}{*}{ Sampel } & \multicolumn{2}{|c|}{ Lama Perendaman (Jam) } & \multirow{2}{*}{$\begin{array}{c}\text { IKS } \\
(\%)\end{array}$} \\
\cline { 2 - 4 } & & 1 & 24 & 72,93 \\
\hline \multirow{3}{*}{$25: 75$} & I & 1504 & 1097 & 98,89 \\
\cline { 2 - 4 } & II & 1359 & 1344 & 80,77 \\
\cline { 2 - 4 } & III & 1602 & 1294 & 77,95 \\
\cline { 2 - 4 } & IV & 1556 & 1213 & 70.96 \\
\cline { 2 - 4 } & V & 1560 & 1107 & 80,30 \\
\hline \multicolumn{2}{|r|}{ Rata-rata } & 1516,36 & 1210,99 & \multicolumn{2}{c}{} \\
\hline
\end{tabular}

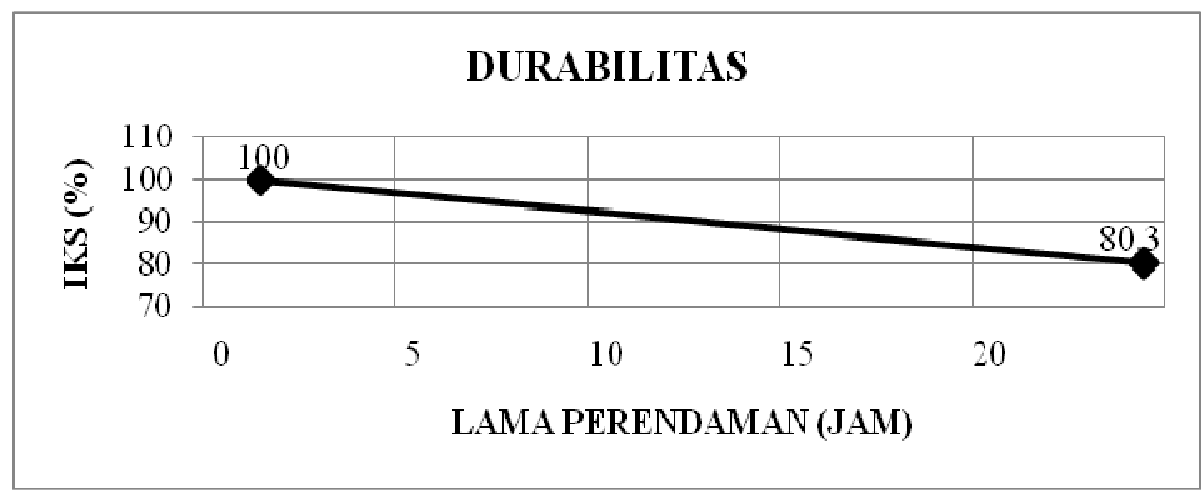

Gambar 3 Kurva Durabilitas Perkerasan AC-BC

Dari grafik diatas diperoleh Indeks Kekuatan Sisa sebesar 80,30\%, dapat dilihat bahwa persentase sisa stabilitas yang direndam selama 24 jam dengan stabilitas standar memperlihatkan perbedaan. Hal ini dikarenakan perendaman benda uji lebih lama dengan suhu $60^{\circ} \mathrm{C}$ menyebabkan butiran-butiran dalam campuran aspal lepas dan mengalami penurunan kekuatan campuran.

\section{Kesimpulan dan Saran}

\subsection{Kesimpulan}

Berdasarkan hasil pengujian dan penelitian yang telah dilakukan dapat diambil kesimpulan sebagai berikut:

1. Penggunaan abu batu kapur dan abu tempurung kelapa dapat digunakan sebagai filler pada campuran aspal beton AC-BC menunjukan bahwa, pada variasi 100:0 dimana nilai density, VMA, VITM, flow dan MQ telah sesuai spesifikasi, sedangkan untuk nilai VFWA dan stabilitas cenderung tinggi yang menyebabkan campuran menjadi kaku dan dapat menyebabkan perkerasan mudah mengalami cracking. Pada variasi 0:100 dimana nilai density, VMA, VITM, stabilitas dan MQ telah sesuai spesifikasi, sedangkan untuk nilai VFWA dan flow cenderung tinggi yang dapat menyebabkan mengalami 
bleeding. Pada variasi 25:75 dimana seluruh nilai karakteristik Marshall telah sesuai spesifikasi yang disyaratkan dan menunjukan pada variasi ini campuran baik untuk digunakan. Pada variasi 50:50 dimana nilai density, VMA, VITM, stabilitas dan MQ telah sesuai spesifikasi, sedangkan untuk nilai VFWA dan flow cenderung tinggi yang dapat menyebabkan campuran menjadi plastis. Pada variasi 75:25 dimana nilai density, VMA, VITM, VFWA, stabilitas dan MQ telah sesuai spesifikasi, sedangkan untuk nilai flow sangat tinggi yang dapat menyebabkan campuran menjadi plastis dan terjadinya bleeding.

2. Penggunaan abu batu kapur dan abu tempurung kelapa dapat digunakan sebagai filler pada campuran aspal beton AC-BC, variasi optimum didapatkan pada variasi filler 25\% abu batu kapur dan $75 \%$ abu tempurung kelapa, dimana nilai stabilitas didapatkan sebesar $1516,36 \mathrm{Kg}$ nilai tersebut telah memenuhi spesifikasi yang disyaratkan yaitu minimal $800 \mathrm{Kg}$. Selanjutnya untuk flow didapatkan nilai sebesar $3,910 \mathrm{~cm}$ dan telah memenuhi syarat antara $2-4 \mathrm{~cm}$. Untuk seluruh karakteristik Marshall lainnya menunjukan bahwa, pada variasi 25:75 menunjukan seluruh nilai karakteristik Marshall telah memenuhi Spesifikasi Bina Marga 2010 Revisi 3 yang disyaratkan.

\subsection{Saran}

Berdasarkan hasil pengujian dan penelitian yang telah dilakukan dilaboratorium dapat diambil saran sebagai berikut:

1. Pada saat pengujian analisa saringan diharapkan pengayakan material lebih baik atau teliti karena pengayakan dilakukan secara manual, agar didapatkan hasil yang lebih akurat.

2. Pada saat percampuran dan memasukkan hot mix dalam cetakan diperlukan alat pencampur dengan akurasi tinggi serta ketelitian yang baik, supaya campuran dapat merata dengan sempurna dan agar tidak ada material yang jatuh/keluar yang dapat menyebabkan volume benda uji menjadi berkurang. Sehingga didapatkan hasil yang lebih baik.

\section{Daftar Kepustakaan}

Anonim, 2010, Tata Cara Pelaksanaan Lapis Aspal Beton (Laston) Untuk Jalan Raya, Direktorat Jendral Bina Marga, Departemen PU, Jakarta

Anonim, 2014, Spesifikasi Umum Bidang Jalan dan Jembatan 2010 Revisi 3, Divisi IV Perkerasan Aspal, Direktorat Jendral Bina Marga, Departemen PU, Jakarta.

Hardiyatmo, H. C., 2011, Perancangan Perkerasan Jalan Dan Penyelidikan

Tanah, Gajah Mada University Press, Yogyakarta.

Said Jalalul Akbar, Wesli, 2014, Studi Korelasi Daya Dukung Tanah Dengan

Indek Tebal Perkerasan Jalan Menggunakan Metode Bina Marga, Teras Jurnal Vol 4 No 1, Jurusan Teknik Sipil Universitas Malikussaleh, Lhokseumawe, hal 61-70

Pengaruh Kadar Filler Abu Batu Kapur Dan Abu Tempurung Kelapa Terhadap Karakteristik Marshall Pada Campuran Aspal Beton AC-BC-Muhammad Tacob, Wesli 
Suprapto, 2004, Bahan Dan Struktur Jalan Raya, Nova, Bandung.

Sukirman, S., 2003. Beton Aspal Campuran Panas, Edisi Pertama, Granit, Jakarta.

Sutopo, J. L., 2015, Pengaruh Variasi Kadar Filler Abu Batu Bara Terhadap Stabilitas Dan Durabilitas Pada Campuran Aspal Beton AC-BC, Skripsi, Universitas Malikussaleh, Lokseumawe.

Wardiyatmoko, K., 2006, Geografi SMA Kelas XI, Erlangga, Jakarta. 